\title{
IMPLEMENTATION OF A SMART HOUSE APPLICATION USING WIRELESS SENSOR NETWORKS
}

\author{
Ismail MOHAMMED $^{1}$ and Erkan DUMAN ${ }^{2}$ \\ ${ }^{1}$ P.G. Student, Department of Information Technology, Technical College of \\ Informatics, Sulaimani Polytechnic University, Sulaimani, Iraq \\ ${ }^{2}$ Asst. Professor, Department of Computer Engineering, Faculty of Engineering, \\ Firat University, 23119 Elazı $\breve{g}$, Turkey
}

\begin{abstract}
Digitisation and automation are becoming increasingly prevalent in our daily lives, both inside and outside the house. They are all attempts to simplify, use easily, monitor and be aware of any devices in a house that are connected to the system. These automated systems can be an alternative to other home manual settings. Smart homes are rarely found in my country, iraq. People's unfamiliarity with them, the lack of use, the costs and a failure to see the importance of such systems are all possible explanations for this. Nowadays, it is generally advancing very rapidly, the internet and smart phones in particular. Using such technology and devices is inevitable and difficult to avoid. Such smart systems are able to indicate and control light, temperature, dew point, gas flow, fire ignition, opening doors and buzzing alarms. Now, as iot is emerging more widely than before, it is expected that IOT will become more prevalent and occupy wider areas of the world. IOT enables a better connection among devices in a smart home or to other smart systems via the internet and WSN. In this paper, a smart home via smart phones and pcs will be explained. Controlling and indicating electrical and electronic devices in houses and buildings will also be presented.
\end{abstract}

\section{KEYWORDS}

Smart home, IoT, Arduino Mega2560 and UNOR3, Ethernet Shield 5100, WSNs, sensors, GSM, Wi-Fi ESP8266-12E, 01, Solar Tracker.

\section{INTRODUCTION}

A smart home is an automated and intelligent home which can be designed and set due to the technology being used [1]. Smart homes can be programmed to fit the client's needs. Programming can lead to a fully automated system where every device in the home can communicate with others via sensors. A smart home can provide good security, convenience, entertainment, good communication, economy and an information system [2].

Different smart house systems have been created where the control is through Android applications, Bluetooth, WIFI, web, call and/or short message administrations (SMS) based

Natarajan Meghanathan et al. (Eds) : NeCoM, SEAS, CMCA, CSITEC - 2017

pp. 53- 70, 2017. (C) CS \& IT-CSCP 2017

DOI : $10.5121 /$ csit.2017.71205 
through GSM808. WIFI capability is great and the vast majority of current devices can be connected easily and co-ordinated so as to reduce the system's costs. Bluetooth's range, however, limits its usage to inside the home [3].

Several methods can be used to secure a smart home, such as: RFID, Password or fingerprint. These smart homes serve well in pre-alarming and controlling the temperature, air-conditioning, bulbs equipped with sensors, gas detecting sensors and flame sensors. As well as all this, a smart home alerts the home owner to thieves and burglars, several unwanted conditions with the use of IR waves. Furthermore, smart home sensors take advantage of different ranges of electromagnetic waves including GSM, IR, Bluetooth and Wi-Fi. With these different frequencies a home's devices are connected in a Wireless Home Area Network (WHAN)[4]

It is also important in this project to alert homeowners to any unwanted events and intruders who might try to enter the house without legal permission. The alert can be given via a ring to a phone, an SMS or an email. More interestingly, the system can be set to alert governmental and national bodies about unwanted accidents in cases when the owner of the house might be travelling to another country. In this way, fire fighters can reach the home and tackle a fire even without the help of the homeowner. Another aspect of this project is to involve the smart house in the upcoming era of the Internet of Things (IoT). Thus, different sections of the house can be accessed via a phone, tablet or PCs [5]. The programs of the system can easily be edited and updated and its problems fixed properly. WHAN, which is established via a Wireless Sensor Network (WSN) and an IP, is granted to each peripheral to run the system via the internet too [6]. Having this access remotely enables the homeowner to perform preparation, such as turning an air conditioner ON for their return while they are away from home. Two types of Wi-Fi have been used: ESP8266 -01,12E. Each of these is important. An Ethernet shield and Router can be used as a third way. A smart home reduces the use of electric energy or can use alternative energy, such as solar energy [7]. It reduces costs and is environmentally friendly [8].

As an Iraqi student I study in Turkey and encountered several problems regarding establishing this project. In Iraq, such systems are new and a smart home designer usually faces numerous problems, like inability to get hold of the pieces for the project, high prices and unreliable delivery of the parts for a project. Such homes are very important for our country in terms of security, economy and a proper use of electricity. Such systems would work very well for those who are disabled and have lost their limbs in the continuous battles in our country [9].

In this paper, a prototype of a smart home is presented. Generally, the system consists of these

parts: WiFi, IR, Keypad, GSM, Ethernet shield, Arduino (Uno and Mega), humidity, Temperature, Gas sensor, Flame sensor, ESP8266-01,12E, Buzzer, PIR and LCD.Numerous trials been carried out before the results of this paper were presented [10].

\section{RELATED WORK}

\subsection{Smart Home System}

Our system runs with Operating Systems (OS) such as Android and the Internet of Things (IoT), which are well known to those who deal with such systems. We have endeavoured to abide by the limitations of commonly used systems. Comfort, security and flexibility are some common features of the system [11]. This system is able to work with android phones, laptops, tablets or a 
PC. The main components are: a board of Arduino (MEGA 2560\& Uno R3), which can be called the brain of the system, a Router, Wi-Fi (Node MCU-ESP8266-12E and ESP8266-01) with a good range, an IR device, an Ethernet shield (network interface W5100), a GSM device and a User device with an Android OS, such as smartphone or computer (through the web). These devices are connected through either the internet or Wireless Application Protocols (WAP). The user controls the entire system through an android enabled device (by either a smart phone or tablet).

The system is also controlled through an IR device (control). This has made the system more desirable and famous, as it does not necessarily need the internet or a wired connection. The WiFi network is the main grid. Through it, the instructions of the user are transmitted. Bluetooth and IR are also used inside the house as alternatives when needed despite their specific importance. The user's necessities are the foundation steps that the system is built upon.

Home appliances are also controlled through a relay circuit, which can be connected to many house devices, like heating, ventilation and air conditioning (HVAC) .

Along with the Arduino and network interface (W5100), the RDIF module and sensors also play a very important role in the system. An RFID (Radio Frequency Identification) reader and a key pad are integrated into the system, to sense the state changes of the main door of the house and to control it (door lock).

RFID is a module to transmit data over a short range. It includes a tag scanner/reader that is capable of scanning as many tags as we set to it. Every tag has an ID that can be determined (authorised or not authorised) [12].

All sensors communicate with a microcontroller (where all input data are processed), depending on the program; the microcontroller decides and sends signals to the user and related relays to operate the house devices.

Therefore, the flame or smoke detection sensor collaborates with an Arduino, which is attached to relays that open to the door and operate the fan when the gas or fire spreads inside the home. The Arduino also signals the buzzer to shoot out and the leads to come on. These all constitute the (fire alarm system) which can call the owner of the house (ringing) through the GSM system.

The GSM system is also activated by Pyroelectric Infrared Sensor (PIR), which is used to detect human bodies as it can detect any change in infrared radiation. When a human passes through this sensor, the temperature in the background will rise from room temperature to the body temperature and thus motion will be detected; i.e. it detects motion. The motion detector sensor collaborates with an Arduino and the GSM808, which contain a mini simcard (mobile simcard) which calls the number saved in the program.

The temperature sensor coordinates with an Arduino that is connected to an LCD and a relay that controls the heater or an air-conditioning system.

The light detector sensors collaborate with an Arduino which is connected to relays that control the lamps. Besides these, this system has a photo sensor (photo resistor) which is economic and friendly to the environment. 
In our work, the essential concepts of the automated house system were included (that is developing daily).

This system has the ability to expand and be integrated as an up-to-date involved system, so new devices and more security levels may be added to the systems..

\subsection{Wireless Sensor Network (WSNs) :}

WSN is a collection of many sensor nodes. Each can sense, process and connect to a microprocessor unit to work together in a coordinated manner (Figure 1). Physical or environmental conditions, such as motion, temperature, humidity, smoke and gas, etc., are monitored by these sensors in a coordinated way [13].

These sensors run through an algorithm to the main control unit (Arduino Node MCU ESP8266$12 \mathrm{E}$ ), which has much more computational power and links and acts as the main way that links the sensor nodes and the end users. The principal features of WSN include power consumption constraints for node; capability of accommodation with node and communication tasks; scalability to large devices; ability to resist hard environmental conditions, mobility of node and variation of nodes [14].

It is the WSN that plays a major part in enabling highly accurate sensor and actuation systems, in homes, buildings and surrounding spaces, by supplying a trusted, cheap and wide solution. Their tools can be used in current, as well as future, structures, without significant changes in the existing infrastructure [15].

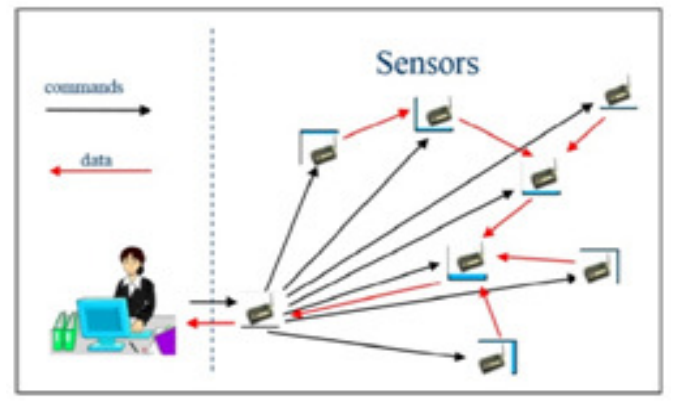

Figure 1 WSN Sensors

\subsection{The Internet of Things:}

The Internet of Things refers to a network of objects where all things are uniquely and universally addressable, identified and managed by computers and smart phones. It is a collection of technologies that make it possible to connect things like sensors and actuators to the Internet (Figure 2) [16][17].

The Internet of Things is defined as an integrated part of the Future Internet and could be defined as a dynamic global network infrastructure with self-configuring capabilities based on standard and interoperable communication protocols where physical and virtual things have identities, physical attributes and virtual personalities, and use intelligent interfaces, and are seamlessly integrated into the information network [18]. 


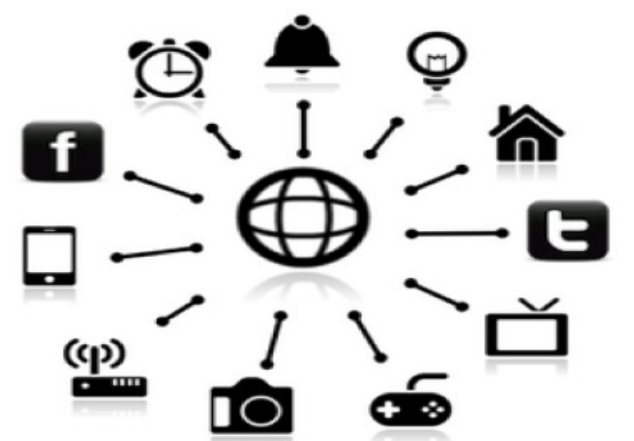

Figure 2 The Internet of Things image.

\subsection{System Block Diagram:}

According to the design needs and desires, the system block diagram (Figure 3) is made. Our block diagram shows all the parts of the system and their functions. The project design follows the modular approach, using an Arduino Mega 2560 (Atmel 2560) microcontroller. The system is intended to enhance security, adaptability and effectiveness. The framework is planned to give ease in everyday life, and additionally spares power and human endeavour. This framework incorporates Arduino, sensors (like LPG gas, PIR, humidity and temperature), LCD show, LAN, 8 Relays channel, RFID, Keypad, smartphone and PC.

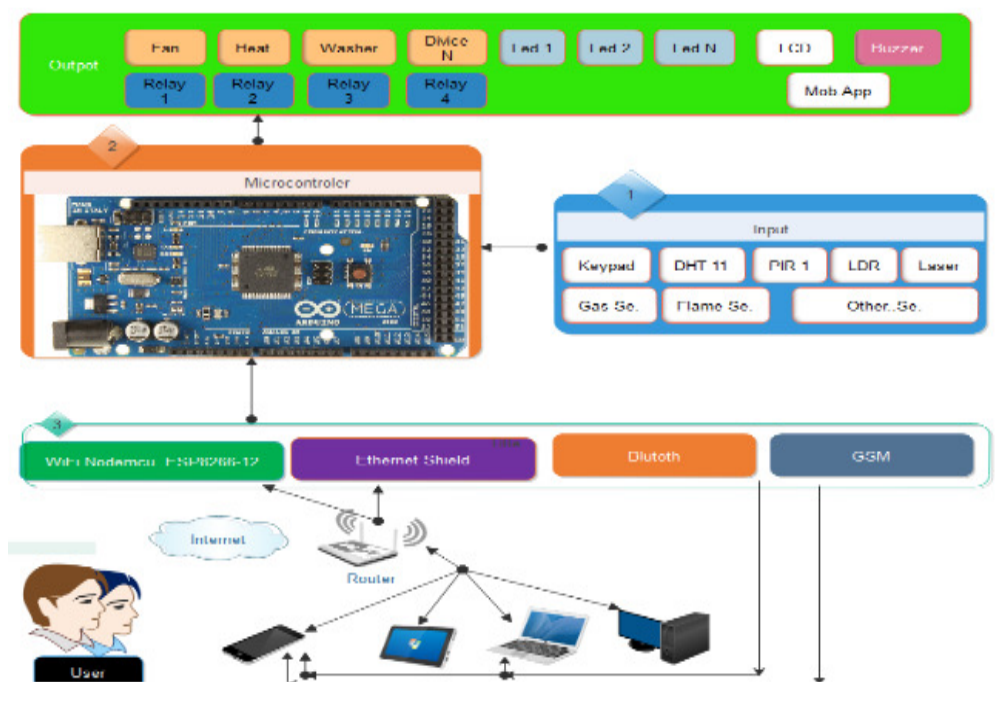

(Figure 3) System Block Diagram.

\subsection{System Implementations}

\subsubsection{Project Flow:}

This section explains the steps that need to be undertaken in order to achieve the goal of the project (Figure 4). 


\section{Gathering the parts needed for the project}

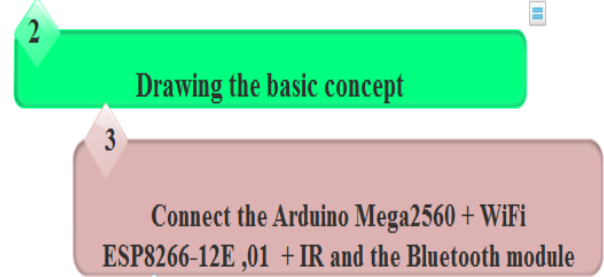

Program the Arduino + Install Library

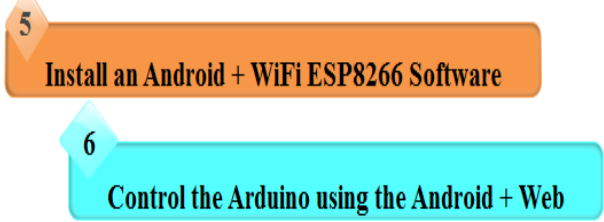

Figure 4 Project Flow

\subsubsection{Hardware Implementation:}

This includes PC, Laptop or Tablet, and Smart Phone, Arduino Mega 2560 (Figure 3.2.), Arduino UNOR3 (Figure 3.2.b), Breadboard Circuit, Ethernet Shield, Router, Led, LCD for Arduino, LDR Sensor, RFID Card System, Motion sensor, Servomotors, Temperature sensor, GSM Modem, smoke sensor and LPG gas sensor.

\subsubsection{Arduino Mega 2560 (Figure 5) and Arduino UNOR3 (Figure 6)}

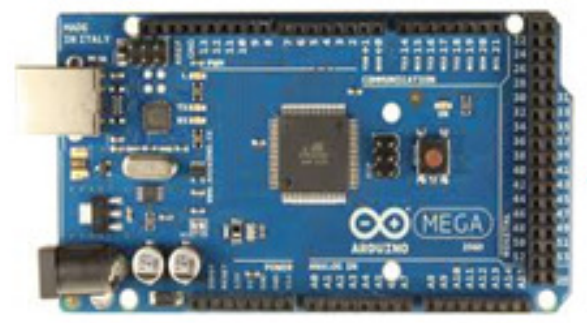

Figure 5 Arduino-Mega2560 Structure.

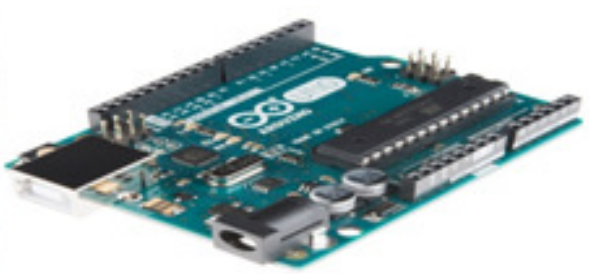

Figure 6 Arduino-UNO Structure.

\subsubsection{WiFi Shield (ESP8266 WIFI SERIAL TRANSCEIVER):}

The ESP8266 Serial-to-WiFi adapter has been widely adopted as a cost-effective solution for IoT and WiFi-capable devices. We used two types of ESP8266 in our project: MCU Node ESP826612E WIFI (Figure 7 and 8) and ESP8266-01 WIFI [19].

MODULE ESP826-01 is a cheap, high quality WiFi module with potent on-board processing and storage capacities [20]. (Figure 9). 

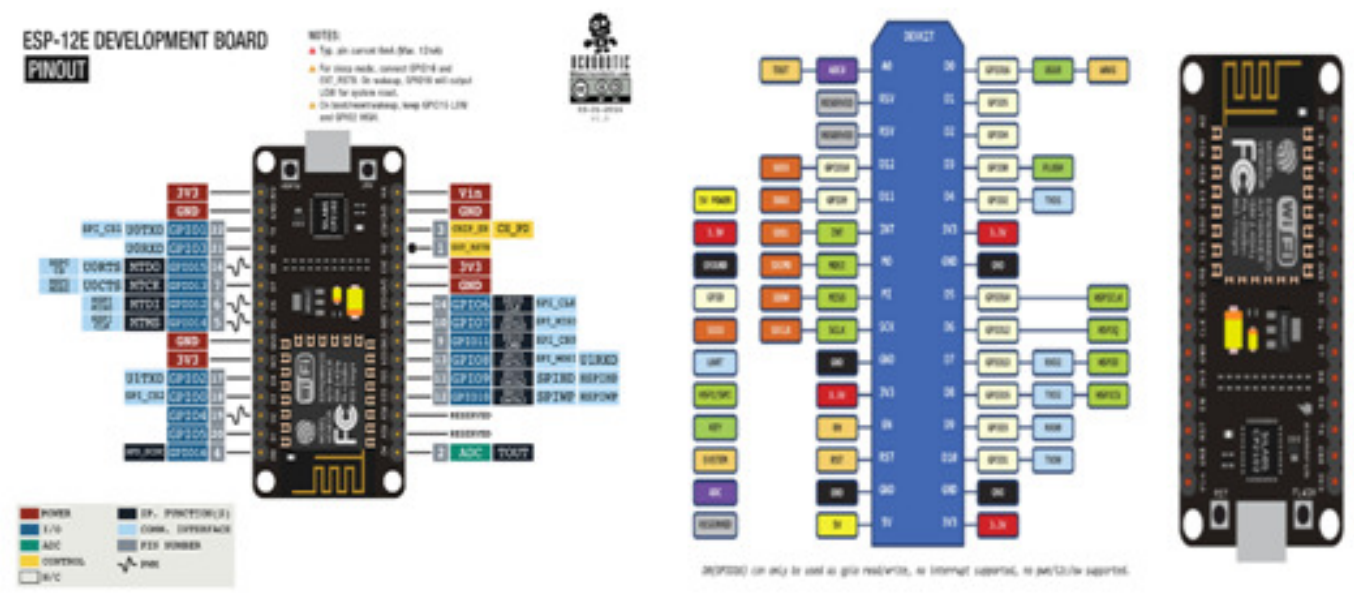

Figure 7 ESP8266-12E WIFI SERIAL TRANSCEIVER.

Figure 8 ESP8266-12E
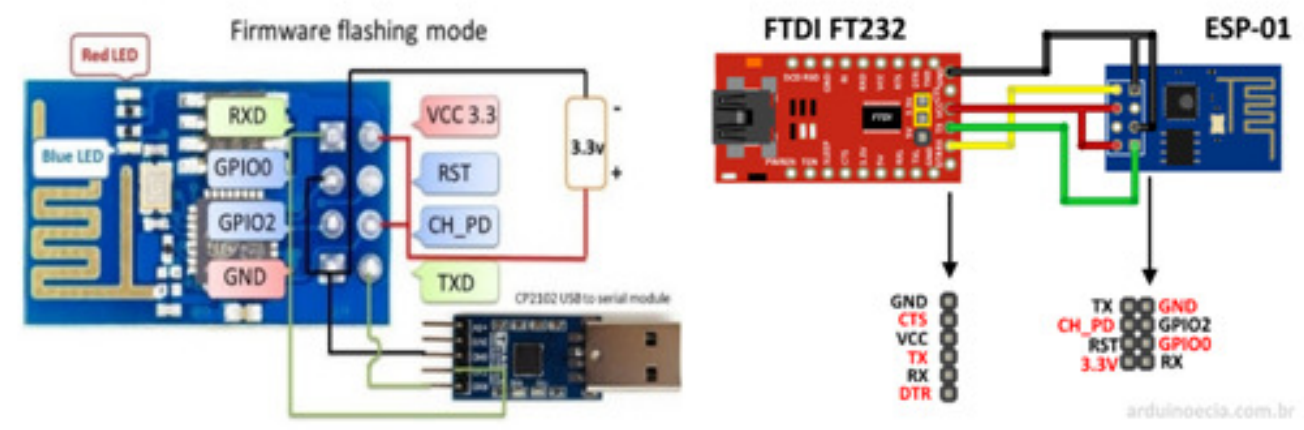

Figure 9 Top View of ESP8266-01

\subsubsection{BluetoothHC-5}

Bluetooth is a short field communication technology (less than 10 metres) and is considered a low energy utilisation. It is not appropriate for all our demands. The information transmission rate is less than that of WI-FI, yet it is still beneficial for our application $(720 \mathrm{~Kb} / \mathrm{s})$ (Figure 10)[21].

\subsubsection{SIM808 Module (GPS-GSM-GPRS):}

SIM808 module is a GSM, GPRS and GPS three-in-one limit module. In light of the latest GSM/GPS module SIM808 from SIMCOM, it supports GSM/GPRS Quad-Band framework and joins GPS innovation for satellite route (shipping). It is controlled by AT charge by methods for UART and sponsorships 3.3V and 5V clever level(Figure 11)[22].

\subsubsection{Ethernet Shield (W5100)}

In our design, W5100 interface has been used (Figure 12) this uses $0.18 \mu \mathrm{m}$ CMOS technology and has 16 Kbytes of memory (TX/RX buffert) to supply a $10 \mathrm{Mb} / 100 \mathrm{Mb}$ Ethernet association [23]. 


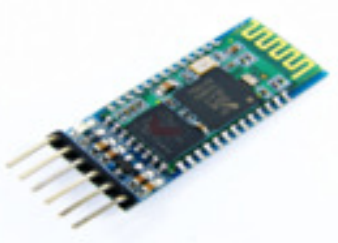

Figure 10 Bluetooth HC-5 device Figure 11 SIM808 Module
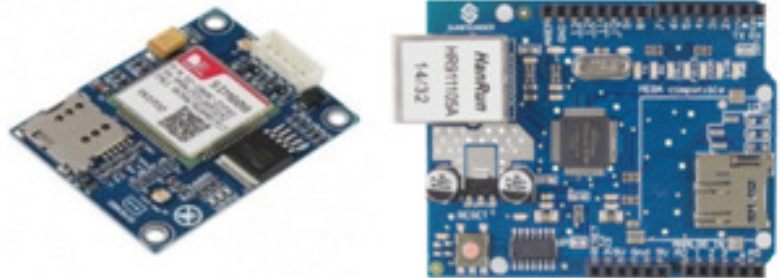

Figure 12 Ethernet shield

\subsubsection{LAN Cable (Local Area Network):}

To get to the web in Arduino LAN connection is required. The LAN speed is considerably quicker than the wireless speed [24] .

\subsubsection{LCD Display:}

LCD display is used to see the present status of the home devices and the sensors (password and temperature).

\subsubsection{Sensors}

The sensors used in this project include: photo resistor (Figure 13 a ), temperature and humidity sensors (DHT11) (Figure 13 b), flame sensor (Figure 13 c), Gas Sensor (MQ-2) (Figure 13 d) and Human Body Pyroelectric Infrared Sensor (PIR) (Figure 13 e).

There are many distinctive gas sensors that recognise LPG, CO2, methane and fire. The case given here utilises the MQ2 sensor to distinguish air quality.

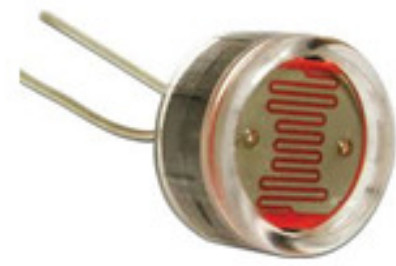

(a). Photo resistor

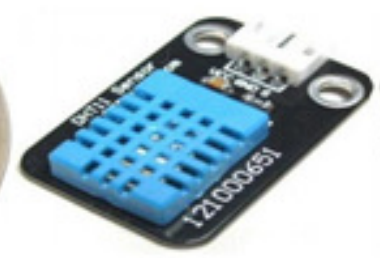

(b). Humidity sensors (DHT11)

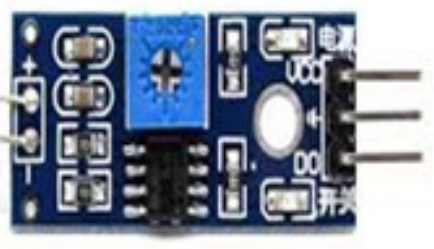

(c). Flame sensor

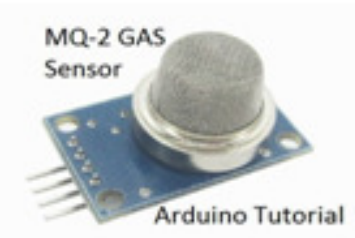

(d). Gas Sensor (MQ-2)
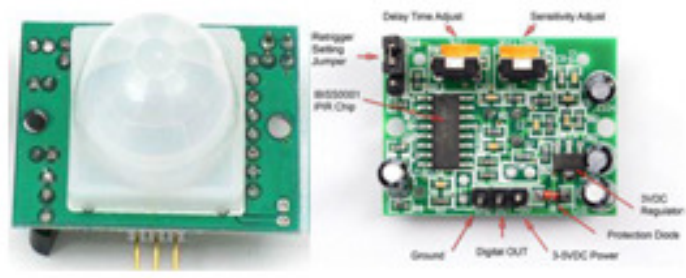

(e). Human PIR Sensor (anterior and posterior views)

Figure 13 (a, b, c, d and e) Sensors used in the project.

The following flowcharts show different sensors and their connection to the Arduinos and how temperature, humidity(Figure 14) and gases are detected (Figure 15): 


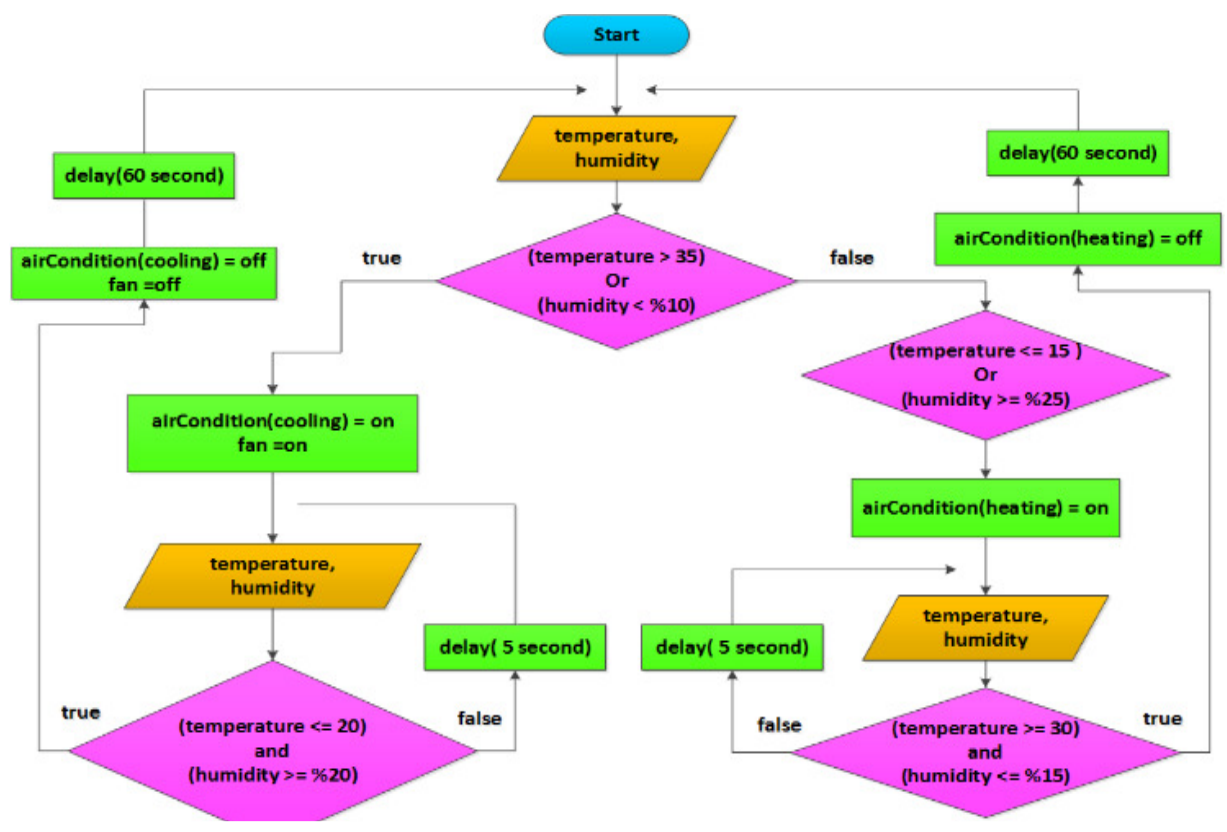

Figure 14. Flowchart of Temperature and Humidity sensors (DHT11).

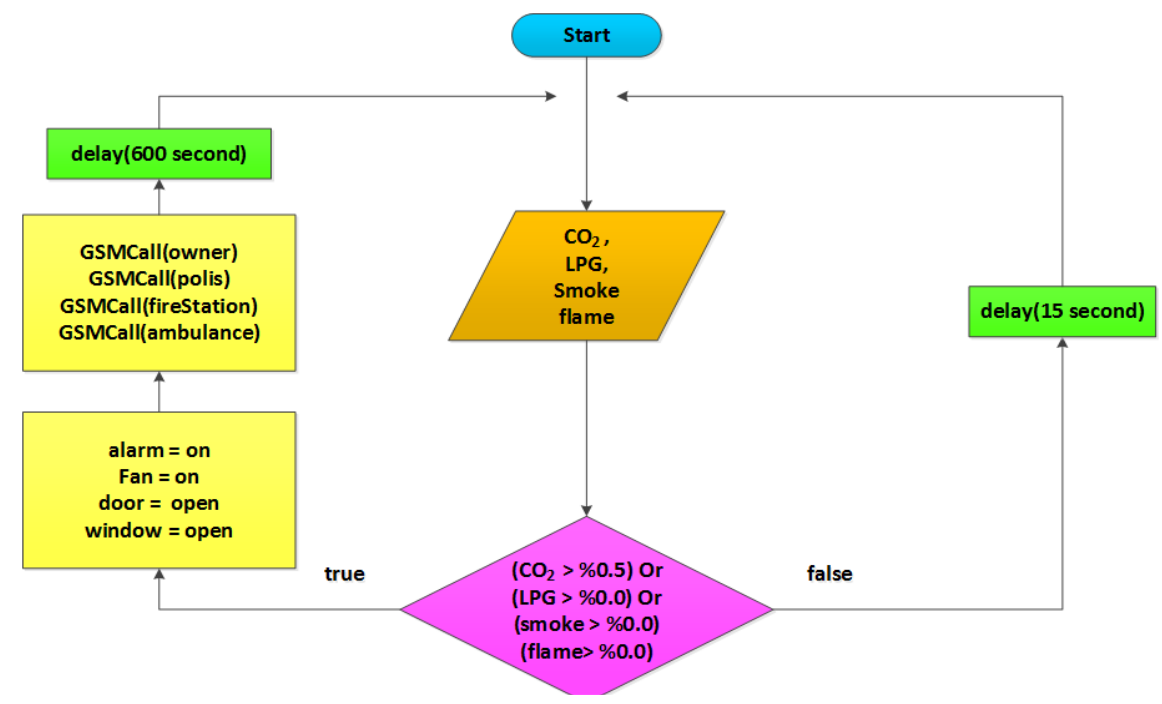

Figure 15. Flowchart of LPG gas sensor and Gas Sensor (MQ-2).

Human Body Pyroelectric Infrared Sensor (PIR): (Figure 13.e) feels any difference in IR radiation. In this manner, it could be utilised to distinguish movement. PIR's IC is BISS0001 Micro Power utilises low-energy CMOS technology. This sensor distinguishes the movement of an individual. As a human passes through this sensor, the background temperature (room temperature) will increase (to the body temperature) and in this manner the movement or human will be recognised [25]. This sensor may be used inside or outside the house. Outside the house: when the password (entered through a keypad) and/or RFID card (Figure 16) is used correctly, the buzzer (shooting) will stop, a green light will go on and the main door will be opened. When an incorrect password is entered or an RFID card is not used or wrongly used, the buzzer remains working, the red light will go on and the main door will remain closed. Inside the house, when the 
PIR sensor is on, if it recognises any motion the buzzer starts to work and the red light goes on. The device starts calling the saved mobile numbers (residents or police station).

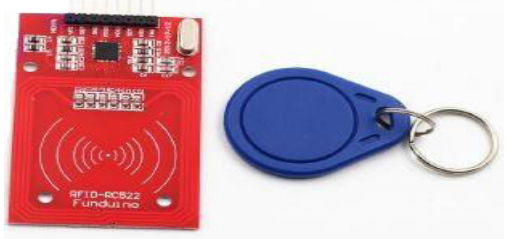

Figure 16 RFID RC522

The following flowcharts (Figure 17 and 18) show the sequence of detection of any motion by PIR and LASER, then alarming through sound (buzzer) an, light and GSM :

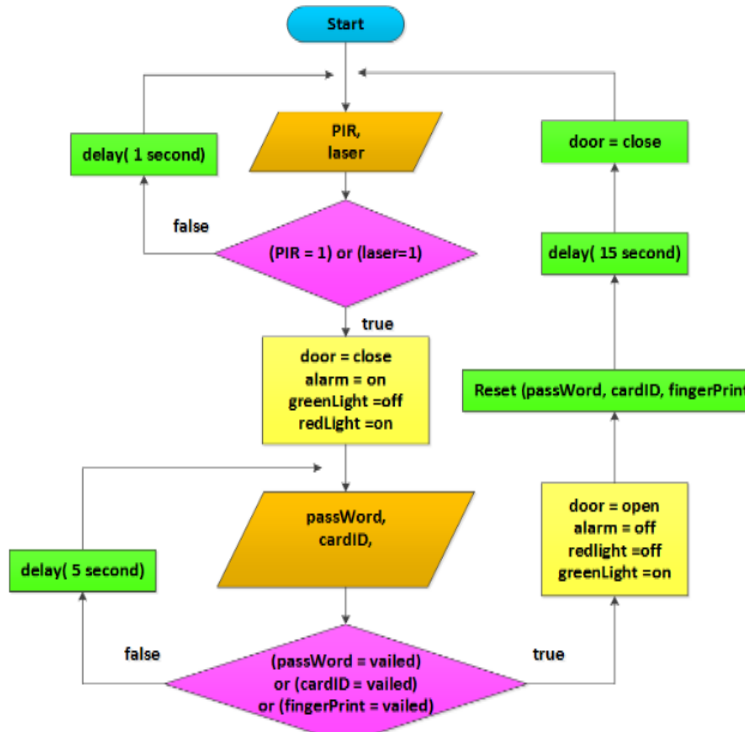

Figure 17. Flowchart of PIR and Laser

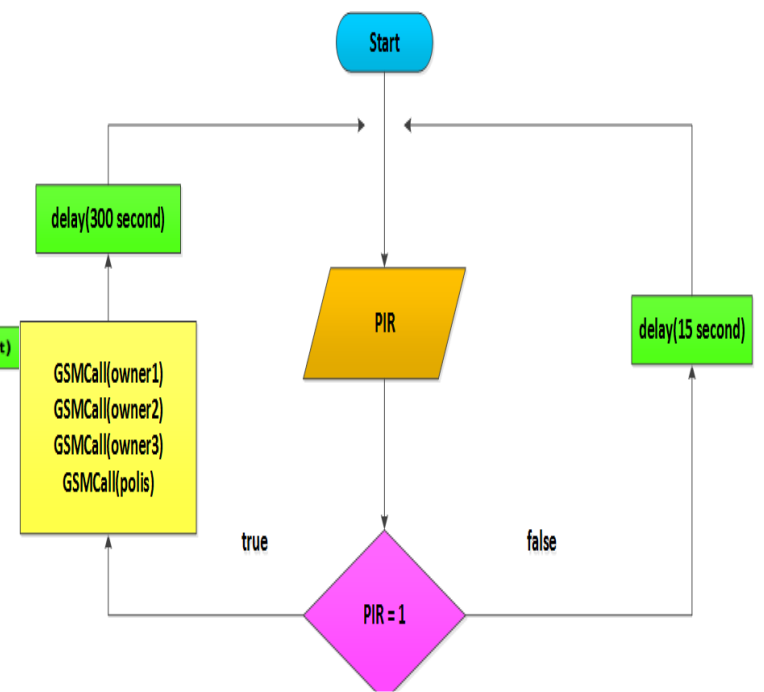

Figure 18. Flowchart of PIR

\subsubsection{Software Implementation: (SYSTEM SOFTWARE DESIGN)}

This part deals with the configuration of the software, program procedures and framework approaches used in programming the Arduinos in our smart home model. The software program roles are receiving information and orders, performing distinctive orders, controlling operational stations and supporting information input/output gates. We have attempted to offer general thoughts on program stream and usage (see flow charts). We divided our design into various parts, contingent upon the useful connection between these parts, to be dealt with easily and when a section or a piece is not working appropriately, it can be detected and treated.

The application created for this work (Arduino IDE 1.8.1) is responsible for the participation, communication and collaboration between the hardware and the portable PC or smart cell. It has been written in $\mathrm{C}$ language to follow the guidelines of coding for the project. WiFi MCU Node ESP8266-12E needs a software introduced inside Arduino IDE [26].

First we install the Arduino Software/IDE, then we open the Arduino program IDE, then select (File), where one can find the (Preferences) Dialog. Choose (Preferences), a (Settings) list will be 
opened, in "Additional Boards Manager URLs" add this line and click on "OK":" http://arduino.esp8266.com/stable/package_esp8266com_index.json "then go to (tools again), from the list choose (board), select (boards manager) at the top. Select "ESP8266" and install it [27].

To determine the type of the board, connect the Board to the PC, then select Device Manager in (my computer). One will see the serial ports in (other devices). Again, select (tools) and choose the COM number (=serial port). In the same list (i.e. tools), choose type of the board (e.g. Node MCU ESP8266-12E or Arduino Mega 2560) [28].

The technique used to outline this product is an upper to lower down organised programming plan. The ports must be defined and determined in the start of the program along with the installing of required libraries then entering the code then uploading, and after that saving the code by a name inside the Arduino`s memory.

After the port locations and definitions, the program initially calls various libraries, e.g. Serial Peripheral Interface (SPI) Library, Ethernet Library, Temperature and Humidity Library and RFID Library.

Our smart home system software involves programming the Arduino by $\mathrm{C}$ and $\mathrm{C}++$ languages (utilising IDE accompanies the microcontroller itself), and Applications such as Arduino IDE 1.8.1 for windows10, ESP8266 WIFI control, Arduino WIFI control and Arduino Bluetooth control device for Android smartphones.

The application program is a NET based application. Entering an IP in the URL of the browser connects the devices to the ESP. The application programs are mindful of setup and arrangement, and keep up the entire smart home system utilising a database to keep log of smart home system parts, we utilise XML files to spare system log.

The Arduino programming is through utilising $\mathrm{C}$ and $\mathrm{C}++$ languages. Utilising IDE accompanies the microcontroller itself. Arduino software collects information about events from associated sensors, then applies activity to devices and what is pre-programmed in the server.

\section{The communication inside the house is through the following:}

1-TP-Link Router that boosts wireless network throughout the home, broadcasting the WIFI that connects MCU Node, ESP8266-12E, ESP8266-01 to smartphone and PC. The Router is also connected to the Ethernet shield via a cable (RJ-45), connecting it to an Arduino.

2-The GSM 808 communicates with a saved mobile number during any event that reaches an Arduino through any connected sensors. When you are outside the home, the communication is through the Internet. Via IoT we can control home devices (e.g. lamps and TV) from far away. 
Table 1.The following table contains the parts of our project:

\begin{tabular}{|c|c|c|c|c|c|}
\hline No & Components & Sensors & Display & $\begin{array}{l}\text { Wireless } \\
\text { Technology }\end{array}$ & Other \\
\hline $\begin{array}{l}1 \\
2 \\
3 \\
4 \\
5 \\
6 \\
7 \\
8 \\
9 \\
10 \\
11 \\
12\end{array}$ & $\begin{array}{l}\text { PC } \\
\text { Smart Mobile } \\
\text { Tablet } \\
\text { Arduino Mega } \\
2560 \\
\text { Arduino UNO } \\
\text { R3 } \\
\text { GSM } \\
\text { GPRS }\end{array}$ & $\begin{array}{l}\text { RFID Card System } \\
\text { LDR Sensor } \\
\text { Motion sensor } \\
\text { Infrared Remote } \\
\text { Control } \\
\text { Temperature node } \\
\text { Light control } \\
\text { Door alarm buzzer } \\
\text { Windows control } \\
\text { Smoke sensors } \\
\text { Gas leakage detection } \\
\text { Flame Sensor } \\
\text { Ultrasonic Sensor }\end{array}$ & $\begin{array}{l}\text { LCD } \\
\text { Monitor }\end{array}$ & $\begin{array}{l}\text { WiFi ESP8266-01 } \\
\text { WiFi Node MCU } \\
\text { ESP8266-12E } \\
\text { Bluetooth HC-5 } \\
\text { IR } \\
\text { Ethernet Shield } \\
\text { Router }\end{array}$ & $\begin{array}{l}\text { Registers } \\
\text { Coil } \\
\text { Switch } \\
\text { Wire } \\
\text { Transistor } \\
\text { Breadboard Circuit } \\
\text { Led } \\
\text { buzzer } \\
\text { Servo motors } \\
\text { Solar panel } \\
\text { tracking system }\end{array}$ \\
\hline
\end{tabular}

\section{EXPERIMENTAL RESULTS}

The planned procedure in building the smart home was successfully applied using equipment such as: WiFi, Sensor, GSM and Arduino in order to operate and administer all the instruments properly.

- The house can detect any body approaching it through PIR or LDR and Laser.

- It can be operated using a personal password by using RFID or Keypad, which turns on a green light that can be seen in the LCD screen.

- After entering the Password or the RFID the door opens automatically and then closes.

- In cases of entering incorrect passwords or using the system incorrectly, a red light and a buzzer turn on to give warning. It enables the user to switch the lights on and off. It also works automatically by turning the indoor and outdoor lights on when it is dark and turning all of them off when there is daylight(Figure 19).

- It also enables the user to check the temperature and humidity in the house, as well as working sensitively to detect any strangers entering the house and the existence of any gas, $\mathrm{CO} 2$, or fire. It also operates to take some necessary reactions and giving the user caution through their mobile phone, as well as operating ventilators and contacting related parties such as fire rescue services, police and ambulance.

- It is worth mentioning that the results can be accessed through web, smart phone and tablet using Bluetooth, WiFi, and IOT (Figure 21) (Figures 20).

- The user can also be informed about the amount of water left in the roof storage tank. They can also stop water consumption at a certain point, which means controlling water consumption for the purpose of protecting it as an important national treasure.

- Reducing energy consumption, which is vital for the environment and the economy at the same time, as most of the equipment only works when necessary.

- The system is also able to draw and close all the curtains and drapes in the house. 
- Using Bluetooth and IR the user is also able to turn on/off and use most of the house equipment.

- All the above-mentioned points facilitate their users in so many aspects which gives them comfort, protection, security and insurance.

- Eventually, by using Solar Tracking generation of light, we managed to obtain more powers of light. The system is able to search for light automatically in a horizontal and a vertical way (Figure 22).

In short, this system is able to work with all its pieces through the internet properly and show the results, as well as performing the tasks using a computer, mobile phone or tablet. It also suggests different ways to activate and use the system properly.

System (IOT):Android implementation`s capacity for loading and carrying out scripts and incorporating a library to create and plan the Android application is valuable in our work. Show the web interface and Android Application Interface that have been used in our system (IOT) (Figures 19 (a, b, c, and d)).

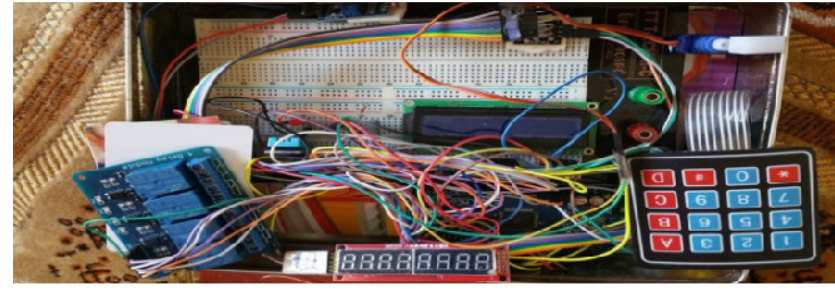

Figure 19. The result of this Control the Home

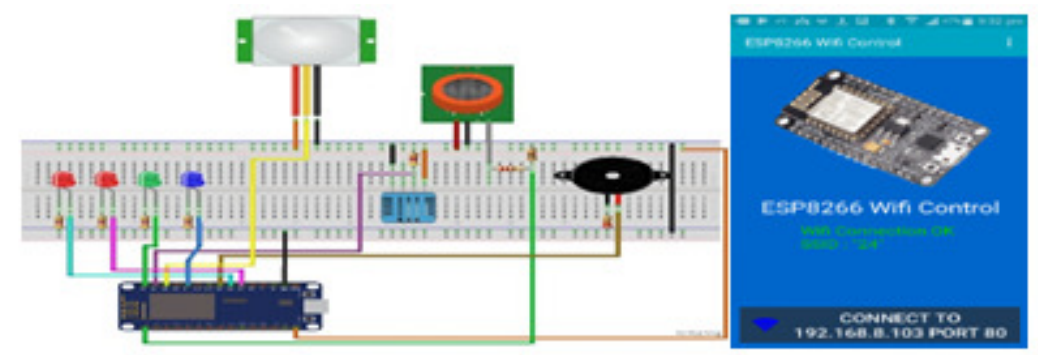

(a) ESP8266-12E WiFi Circuit (b) ESP8266-12E WiFi Control

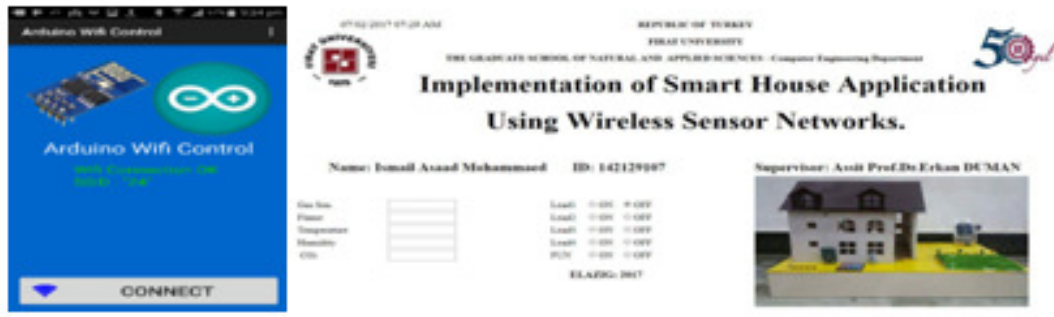

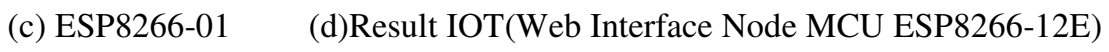

Figures 20. Android Application Interface and Web using WIFI used in our system. 
Bluetooth System: Android Application Interface using Bluetooth that has been used in our system with relays(for AC) (Figure 21 (a, b, c, d and e)).
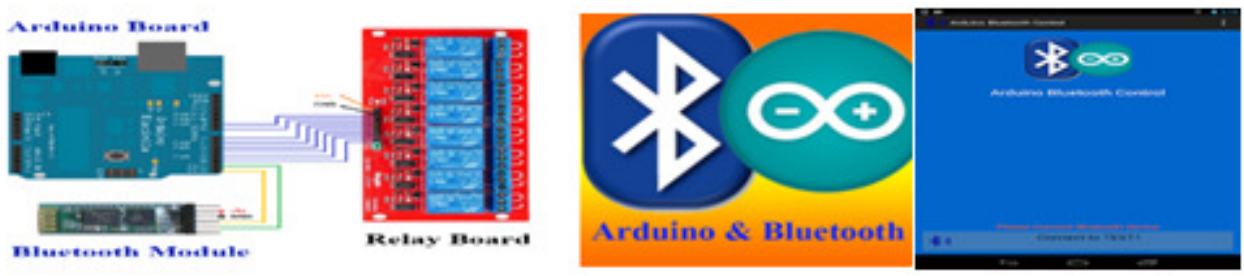

(a) Bluetooth HC-05. (b) Arduino Bluetooth Control Device (c) Arduino Bluetooth Control
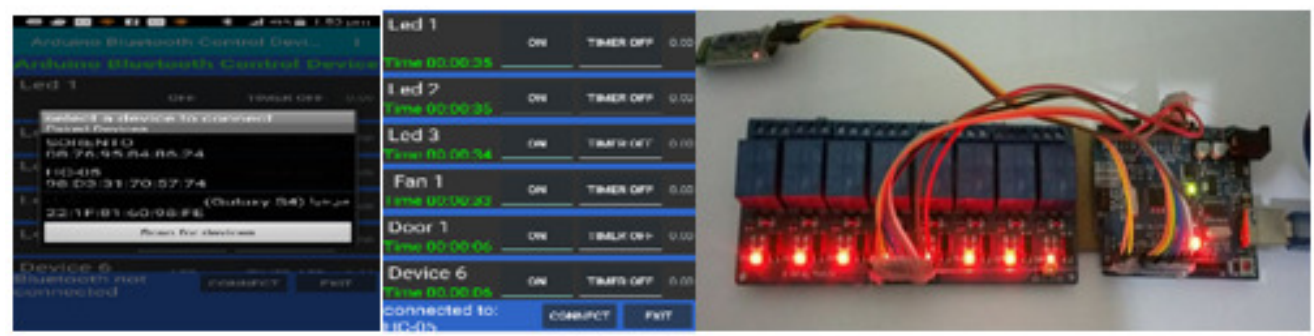

(d)Connects mobile and Bluetooth. (e)Setting the application. (e) Result the Bluetooth Section.

Figure 21. Android Application Interface using Bluetooth that has been used in our system.

Solar Tracker: In this section result of the project which is specific in (Figure 22).

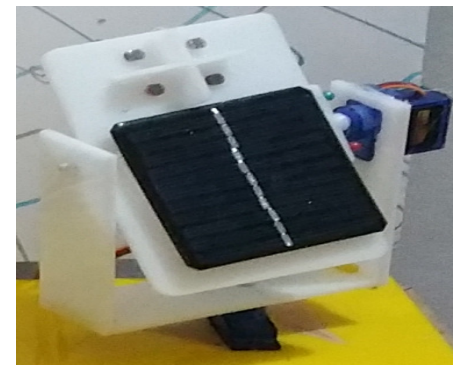

Figure 22. Solar Tracker

\section{CONCLUSION}

- Nowadays, technology has developed in so many ways. In this respect, smart homes could be built considering the following important points:

1. Making sure they are strong and effective as well as being user friendly.

2. Considering security and safety aspects.

3. Making sure it costs little and is economic.

4. For the development of this project, the Solar Tracking generation of light is used to save more energy.

5. Building in a way which leads to less energy consumption and is environmentally friendly.

6. Making sure it is easy to develop as well as easy to mend. 
- Smart home is able to connect a number of machines and sensors together and enables them to work properly and automatically. It also facilitates its users, especially disabled people.

- In this paper, Smart Home Security is considered, so as to be applied properly. It suggests two different ways to connect it to internet, so that it can be used and observed from a distance. This can be achieved through the web by using a PC, laptop, smart phone and tablet after entering their special IP and connecting them together through WSN.

- The paper also suggests using more than one type of wireless, such as IR, Bluetooth and $\mathrm{WiFi}$, in the same project.

- In case of any unexpected incidents, such as strangers entering the house, the existence of fire, smoke, $\mathrm{CO} 2$ gas, or gas exposure, etc. the project suggests building a relationship between the smart home, its user and related parties through GSM.

- The paper also focuses on protecting the environment, reducing electrical energy consumption and avoiding the waste of water. These are the main points, as the mentioned sources are among the main issues in our country as well as being the primary daily needs that are not available these days.

- It is recommended to develop this project and connect it to Face Recognition and Voice Recognition, which aims to enhance the facility and provide more safety and security at the same time.

- It also considers children, patients and elderly people in order to provide them with better care, by observing and watching their movement, safety, body temperature, heart beats, etc. so that the system contacts the owner and ambulance services in any problematic situations.

\section{Advantages of our System:}

The implementation of a Smart House Application Using Wireless Sensor Networks was managed successfully as it was user friendly and cost effective, because of better flexibility via an android device through the web and a wider range of scalability. This system provided comfort, authentication and security.

\section{Future Recommendations}

1. Each component is able to be tested before using them, especially the relays for safety purposes.

2. Instead of WiFi, IR and Bluetooth modules, try LiFi technology which is 100 times faster than WiFi and which amplifies the signal for working at a greater distance. 


\section{REFERENCES}

[1] Jackie Craven, "What Is a Smart House?" [Online]. Available:

http://architecture.about.com/od/buildyourhous1/g/smarthou e.htm. [2017, May 14].

[2] Andi Adriansyah, Akhmad Wahyu Dan, "Design of Small Smart Home System Based on Arduino", Electrical Power, Electronics, Communications, Controls, and Informatics Seminar (EECCIS), Malang, Indonesia, 121 p., 2014.

[3] Mohd Nor Azni, M. N. H., Vellasami, L., Zianal, A.H., Mohammed, F. A.., Mohd Daud, N. N., Vejasegaran, R; N. W.Basharudin; Jusoh, M; Ku Azir, K.N.F., P. L. Eh Kan. "Home Automation System with Android Application", 3rd International Conference on Electronic Design (ICED), August 11-12, 2016, Phuket, Thailand.

[4] Jen Rossey, Ingrid Moerman, Piet Demeester, Jeroen Hoebeke, "Wi-Fi helping out Bluetooth Smart for an improved home automation user experience", Ghent University - iMinds, Department of Information Technology (INTEC),Technologiepark-Zwijnaarde 15, 9052 Ghent, Belgium, 978-15090-4361-3/16/\$31.00 @2016 IEEE.

[5] "Internet of Things Strategic Research and Innovation Agenda" p. 24

[6] Hemant Ghayvat, Subhas Mukhopadhyay, Xiang Gui and Nagender Suryadevara, "WSN- and IOTBased Smart Homes and Their Extension to Smart Buildings".

[7] Oihane Kamara-Esteban, Gorka Sorrosal, Ander Pijoan, Tony Castillo-Calzadilla, Xabier IriarteLopez, Ana M. Macarulla-Arenaza, Cristina Martin, Ainhoa Alonso-Vicario, Cruz E. Borges, "Bridging the Gap between Real and Simulated Environments: a Hybrid Agent-Based Smart Home Simulator Architecture for Complex Systems", 2016 Intl IEEE Conferences on Ubiquitous Intelligence \& Computing, Advanced and Trusted Computing, Scalable Computing and Communications, Cloud and Big Data Computing, Internet of People, and Smart World Congress, 2016 IEEE pp. 220-227. DOI: 10.1109/UIC-ATC-ScalCom-CBDCom-IoP-SmartWorld.2016.116 https://www.researchgate.net/publication/305710190_Bridging_the_Gap_between_Real_and_Simulat ed_Environments_a_Hybrid_Agent-

Based_Smart_Home_Simulator_Architecture_for_Complex_Systems

[8] Mohamed Hadi Habaebi, Nur Izzati Nabilah Bt Azizan, "Harvesting WiFi Received Signal Strength Indicator (RSSI) For Control/Automation System In SOHO Indoor Environment with ESP8266", Department of Electrical and Computer Engineering, IIUM habaebi@iium.edu.my,416-418pp.

[9] Taylor, Joseph, et al. "SenseBox: A low-cost smart home system." Pervasive Computing and Communications Workshops (PerCom Workshops), 2017 IEEE International Conference on. IEEE, 2017.

[10] R.Aravindhan, M.Ramanathan, D.SanjaiKumar, R.Kishore, "HOME AUTOMATION USING Wi-Fi INTERCONNECTION",Department of Mechatronics engineering, Chennai Institute of Technology, Anna University Chennai, Tamil Nadu, India- 600069, (IRJET) e-ISSN: 2395 -0056 Volume: 04 Issue: 03 I Mar -2017, www.irjet.net.2542-2544pp.

[11] Andi Adriansyah, Akhmad Wahyu Dani, "Design of Small Smart Home System Based on Arduino" Department of Electrical Engineering, Faculty of Engineering, Universitas Mercu Buana Jl. Raya Meruya Selatan, Kembangan, Jakarta, 11650, Indonesia,121p. 
[12] Ehsan Dolatshahi, "Smart Home Automation System." CALIFORNIA STATE UNIVERSITY, NORTHRIDGE. December 2015. 35p.

[13] Mantoro, Teddy and Ayu, Media Anugerah and Ali, Haroon Shoukat, Usino, Wendi and Kadhum, Mohammed M. (2012), "Energy efficiency mechanisms using mobile node in wireless sensor networks". Networked Digital Technologies: Communications in Computer and Information Science, 293. pp. 536-550. ISSN 1865-0929.

http://irep.iium.edu.my/24767/1/Energy_Efficiency_Mechanisms_Using_Mobile_Node.pdf

[14] Andreas Kamilaris, “ENABLING SMART HOMES USING WEB TECHNOLOGIES”, University of Cyprus. December, 2012.

[15] Karwan MUHEDEN, Ebubekir ERDEM, "Mobile Design and Implementation Fire Alarm System Using Wireless Sensor Network", Firat University,2017.

[16] Andreas Kamilaris, "ENABLING SMART HOMES USING WEB TECHNOLOGIES", University of Cyprus. December, 2012. 60p.

[17] Muhammad Asadullah, Ahsan Raza, "An Overview of Home Automation Systems", National University of Computer and Emerging Sciences Peshawar, Pakistan, 978-1-5090-4059-9/16@2016 IEEE ,30p.

[18] Internet of Things - Strategic Research Roadmap (IoT-SRR). 15 September, 2009.

[19] http://espressif.com/products/hardware/esp8266ex/overview/

[20] Rui Santos, "Home Automation Using-Esp8266”,2nd Editions, Version 2.1.

[21] Muhammad Asadullah, Ahsan Raza, "An Overview of Home Automation Systems", National University of Computer and Emerging Sciences Peshawar, Pakistan, 978-1-5090-4059-9/16@2016 IEEE ,27-29pp.

[22] R.HARINATH, Dr. S. Santhi, "GSM BASED HOME AUTOMATION SYSTEM USING APPINVENTOR FOR ANDROID MOBILE PHONE”, IJCSMC, Vol. 4, Issue. 4, April 2015, pg.158 167,158-159pp.

[23] Andi Adriansyah, Akhmad Wahyu Dani, "Design of Small Smart Home System Based on Arduino" Department of Electrical Engineering, Faculty of Engineering, Universitas Mercu Buana Jl. Raya Meruya Selatan, Kembangan, Jakarta, 11650, Indonesia,126p.

[24] Shruti G. Suryawanshi1, Suresh A. Annadate, "Implementation of Smart Home Automation System through E-mail using Raspberry Pi and Sensors", Electronics Engineering Dept., M.G.M's Jawaharlal Nehru Engg., College, Aurangabad, India, DOI 10.17148/IJIREEICE. 2016.4347,181p.

[25] https://www.arduino.cc/en/main/software accessed on May 1st, 2017.

[26] http://blog.ubidots.com/esp8266-arduino-ide-tutorial accessed on May 1st, 2017.

[27] Rui Santos ,"ESP8266 Web Server with Arduino IDE”, accessed on jul 2017. 


\title{
AUTHORS
}

\author{
Ismail Asaad MOHAMMED \\ Nationality: Iraqi \\ Place of birth: $\quad$ Sulaimani-Iraq \\ Date of birth: $\quad 01$ / 07 / 1972 \\ Marital status: Married \\ Mobile: $\quad$ 00964(0)7701537418 - $00964(0) 7501537418$ \\ E-mail: $\quad$ ismail.asaad@spu.edu.iq \\ ismailasaad1972@gmail.com
}

\section{EDUCATION}

2/2015 - Started MSc (Master of Computer Engineering Department), Firat University, Elazig, Turkey. 9/2003 - 7/2007 Bachelor degree from Kirkuk University, College of Science, Computer Science Dep. Iraq, Kirkuk.

9/2010 - 6/2012 Diploma, Institute of Sermon in Sulaimani, Iraq.

9/1991 - 6/1993 Diploma, Medical Institute. Institute of Technology in Mosul, Mosul, Iraq.

9/1988 - 6/1991 Higher School from Chamchammal Preparatory School, Sulaimani, Iraq.

9/1985 - 6/1987 Intermediate School, Ronaky Intermediate School, Sulaimani, Iraq.

9/1978 - 6/1984 Primary School, Chamchammal Primary School, Sulaimani, Iraq.

\section{WORK EXPERIENCES}

- Volunteer as Assist. Doctor at faqya Merza health centre 8/1996-5/1997.

- Assist. Doctor at Shahid Peshraw Hospital 5/1997-10/2010.

- Visiting Teacher at Dukan Technical Institute (Practical Teaching). 10/2007 - 02/2013.

- IT department decision's at Computer Science Institute 10/2012-07/2014.

- Teacher Computer Science at Sardam Nongovernmental Computer Institute. 10/2013.

- Assistant programmer at Sulaimani Polytechnic University 07/2014.

\section{Erkan DUMAN}

Nationality:

Place of birth:

Date of birth:

Marital status:

Mobile:

E-mail:

\section{EDUCATION}

$2003-2010$

$2001-2003$

$1997-2001$

\author{
Turk \\ Elazig - TURKEY \\ 02 / 02 / 1979 \\ Single \\ $0090(0) 5336604963$ \\ erkanduman@firat.edu.tr \\ erkan_duman@hotmail.com
}

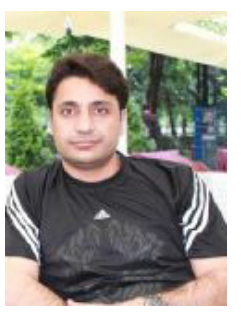

PhD., Electric Electronic Engineering Department, Firat University, Elazig, TURKEY. Master, Computer Engineering Department, Firat University, Elazig, TURKEY.

Undergraduate, Computer Engineering Department, Firat University, Elazig, TURKEY.

\section{WORK EXPERIENCES}

- $\quad$ Research Assistant, Computer Engineering Department, Firat University, Elazig- TURKEY, 20012011

- $\quad$ Asst. Prof., Computer Engineering Department, Firat University, Elazig- TURKEY, 2011-2017 